\title{
In vitro antioxidant activities of sulfated polysaccharide ascophyllan isolated from
}

4 Ryogo Abu ${ }^{\text {a }}$, Zedong Jiang ${ }^{\mathrm{b}}$, Mikinori Ueno ${ }^{\mathrm{b}}$, Takasi Okimura ${ }^{\mathrm{c}}$, Kenichi Yamaguchi ${ }^{\mathrm{a}, \mathrm{b}}$, and 5 Tatsuya Oda ${ }^{\text {a, bq }}$

6

$7 \quad{ }^{a}$ Division of Biochemistry, Faculty of Fisheries, Nagasaki University, 1-14 Bunkyo-machi,

8 Nagasaki, Nagasaki 852-8521, Japan

9

$10{ }^{\mathrm{b}}$ Graduate School of Science and Technology, Nagasaki University, 1-14 Bunkyo-machi, 11 Nagasaki, Nagasaki 852-8521, Japan

12

${ }^{\mathrm{c}}$ Research and Development Division, Hayashikane Sangyo Co., Ltd., Shimonoseki, Yamaguchi 14 750-8608, Japan

9Corresponding author. Fax: +81-95-819-2831. E-mail address: t-oda@nagasaki-u.ac.jp (T. Oda) 


\section{Abstract}

2 Antioxidant activities of sulfated polysaccharide ascophyllan from Ascophyllum nodosum was

3 investigated in vitro by various assays, and compared with those of fucoidan. A

4 chemiluminescence (CL) analysis using a luminol analog, L-012, showed that ascophyllan

5 scavenges superoxide, and the activity is greater than fucoidan. However, in the presence of 10

$6 \mu \mathrm{g} / \mathrm{ml}$ of ascophyllan or $10 \mu \mathrm{g} / \mathrm{ml}$ and $100 \mu \mathrm{g} / \mathrm{ml}$ of fucoidan, slightly enhanced CL-responses were observed. Since EDTA-treatment resulted in disappearance of the enhancement effects, it was suggested that metal ions especially iron ions in the polysaccharides might be involved in

9 this phenomenon. In fact, metal element analysis revealed that ascophyllan and fucoidan

10 inherently contain iron and other metal elements. EDTA-treatment resulted in significant

11 increase in $\mathrm{Fe}^{2+}$-chelating activities of these polysaccharides. In an electron spin resonance

12 (ESR)-spin trapping analysis in which direct UV-radiation to hydrogen peroxide was used as a source of hydroxyl radical, ascophyllan and fucoidan showed potent hydroxyl radical scavenging activity with similar extent. Reducing power of ascophyllan was stronger than that of fucoidan. Our results indicate that ascophyllan can exhibit direct and potent antioxidant activity. 


\section{Introduction}

Reactive oxygen species (ROS) such as superoxide anion $\left(\mathrm{O}_{2}{ }^{-}\right)$, hydroxyl radical $(\cdot \mathrm{OH})$, hydrogen peroxide $\left(\mathrm{H}_{2} \mathrm{O}_{2}\right)$, and singlet oxygen $\left({ }^{1} \mathrm{O}_{2}\right)$ are generated in normal cellular metabolic processes including respiration, as well as by ultraviolet light, ionizing radiation, and various chemical reactions. In living organisms, ROS levels are controlled by certain enzymes such as superoxide dismutase and catalase, and various antioxidant agents. However, uncontrolled overproduction of ROS can often lead to oxidative stress that in turn causes damage to lipids, proteins, and DNA. Thus, the oxidative damages caused by ROS are considered to be involved in a number of pathological conditions including cancer and other various severe diseases [1-4].

The usefulness of polysaccharides and their derivatives in food, agriculture, and medicine has been well documented [5, 6]. Especially indigestible polysaccharides provide various beneficial effects such as lowering blood cholesterol level and blood pressure, and protective effect on infectious and inflammatory diseases [7]. Some polysaccharides are even known as potent immune modulators [8, 9]. In recent years, considerable attention has directed to seaweeds as a rich source of polysaccharides with antioxidant activity [10].

Seaweed-derived polysaccharides such as alginate, fucoidan, carrageenan, laminaran, and agar are known to have various biological activities. Among them, fucoidan has particularly been attracting a great attention in diverse research fields as promising sources for new drugs and health foods or supplements. Fucoidan is a sulfated fucan containing fucose as a main component and uronic acids, galactose, and xylose as minor compositions [11]. Fucoidans isolated from different seaweeds have structural similarity to heparin as a common feature, and they show potent anticoagulant [12] and antithrombotic activities [12, 13]. Fucoidans show numerous other biological properties such as antiviral $[14,15]$, antitumor, anti-inflammatory [16, 17], immuno-modulatory [18], and apoptosis-inducing activities [19, 20]. In addition to these biological activities, it has been reported that fucoidan is capable of scavenging free radicals in vitro [21].

Ascophyllan (xylofucoglycuronan) isolated from a brown alga, Ascophyllum nodosum, is a 
sulfated polysaccharide structurally similar but distinguishable from fucoidan [22, 23]. In our previous study, the presence of ascophyllan was confirmed as a separated fraction from the fucoidan fraction in the extracts prepared from A. nodosum [24]. We found that ascophyllan showed a growth-promoting activity on MDCK cells, while fucoidan was rather toxic to this cell line [25]. Furthermore, our previous studies showed that ascophyllan had capability to induce the secretion of cytokines such as tumor necrosis factor- $\alpha$ (TNF- $\alpha$ ) and granulocyte colony-stimulating factor (G-CSF) from mouse macrophage RAW264.7 cells [24]. Recent study has also demonstrated that ascophyllan induced much higher level of nitric oxide (NO) production from RAW264.7 cells than those induced by fucoidans isolated from Fucus vesiculosus and Ascophyllum nodosum [26]. Reverse transcription polymerase chain reaction (RT-PCR) and western blot analysis revealed that the expression level of inducible NO synthase (iNOS) in ascophyllan-treated RAW264.7 cells was much higher than the levels induced by fucoidans [26]. These results suggest that ascophyllan is an attractive polysaccharide with multiple bioactivities. However, there is no available information on the antioxidant activities of ascophyllan, while fucoidan is known to have antioxidant activity. It is considered that evaluation of antioxidant properties of ascophyllan may provide not only an insight into the underlying action mechanisms for the bioactivities, but also a tip for possible usefulness of this polysaccharides as an antioxidant such as safety food additives. Therefore, in this study, antioxidant activities of ascophyllan in terms of comparison with fucoidan were investigated in various in vitro systems.

\section{Materials and methods}

\subsection{Materials}

Fucoidan from Fucus vesiculosus was purchased from Sigma (St. Louis, MO, USA). 8-amino-5-chloro-7-phenylpyrido [3,4-d] pyridazine-1,4-[2H,3H] dione (L-012), Hypoxanthine, xanthine oxidase, and catalase were obtained from Wako Pure Chemical 
Industries, Ltd. (Osaka, Japan). 5,5-dimethyl-1-pyrroline $N$-oxide (DMPO) was from LABOTEC Co., LTD. (Hiroshima, Japan). Ferrozine and potassium ferricyanide were from Kanto Chemical Co., Inc (Tokyo, Japan). Other chemicals were of the highest grade commercially available.

\subsection{Preparation of ascophyllan from A. nodosum}

Ascophyllan was prepared from the powdered A. nodosum as separated fraction from fucoidan as described previously [24, 25]. Chemical structural analysis confirmed that ascophyllan used in this study had characteristic monosaccharides composition and sulfate level as reported previously [24]. Ascophyllan solution was passed through an endotoxin-removal column (Detoxi-gel: Thermo Fisher Scientific Inc., Rockford, IL USA), and subsequently filtered through an endotoxin-removal filter (Zetapor Dispo: Wako Pure Chemical industries, Ltd, Osaka, Japan). To remove metal ions from ascophyllan and fucoidan, EDTA (final $50 \mathrm{mM}$ ) was added to each sample solution in distilled water and incubated for $6 \mathrm{~h}$ at $25^{\circ} \mathrm{C}$, and then the solution was dialyzed against distilled water for $72 \mathrm{~h}$ with stirring. The solution was lyophilized and the powdered samples were stored at $-25^{\circ} \mathrm{C}$ until use.

\subsection{Superoxide anion $\left(\mathrm{O}_{2}^{-}\right)$scavenging activity}

To study the superoxide scavenging activity of polysaccharide samples, the hypoxanthine (HPX)- xanthine oxidase (XOD) reaction was applied for superoxide generation. L-012 is an analogue of luminol, and L-012-dependent chemiluminescence (CL) reaction has been well documented as a highly sensitive superoxide detection system [27]. A reaction mixture containing $10 \mu \mathrm{l}$ of sample solution in PBS or solvent (PBS) alone and $10 \mu \mathrm{l}$ of XOD (0.02 units/ml) was dispensed into each well of a 96-well microplate. The reaction was initiated by the addition of $80 \mu \mathrm{l}$ of PBS solution containing L-012 (final $100 \mu \mathrm{M}$ ) and HPX (final $500 \mu \mathrm{M}$ ), and the CL intensity of each well was recorded immediately for 10 min using a CL microplate 
recorder (Mithras LB940, Berthold Technologies GmbH and Co. KG., Bad Wildbad, Germany).

\subsection{Analysis of metal ions}

To analyze metal ions in polysaccharide samples, polysaccharide samples were digested by microwave-assisted nitric acid digestion procedure. To each sample (50 mg) in reaction vessel, $5 \mathrm{ml}$ conc. $\mathrm{HNO}_{3}$ was added. The sample was subjected to microwave digestion using a multiwave microwave digestion system (Perkin Elmer, Inc., Kanagawa, Japan). The digested sample was made up to $50 \mathrm{ml}$ with ultrapure water, and then subjected to inductively coupled plasma optical emission spectrometry (ICP-OES) by using ICP-OES ULTIMA 2 (Horiba, Ltd, Kyoto, Japan). The spectrometer with a radial viewed configuration that was equipped a radio frequency (RF) generator (40 MHz), a cyclonic glass spray chamber, a concentric glass nebulizer, and a charge couple device (CCD) detector was employed for the determinations of Mg, Fe, Ni, Zn, Mn, Cr, Mo, Pb, Cd, Co, Al, V, Cu, and Ti. The instrumental conditions as optimized for the analysis of the concentrations of metal ions in the samples are summarized in Table 1.

\section{5. $\mathrm{Fe}^{2+}$-chelating activity}

The chelating activities of ascophyllan and fucoidan on $\mathrm{Fe}^{2+}$ were measured by the method described previously [28]. Two hundred twenty $\mu$ l of sample solution in distilled water, $814 \mu 1$ of distilled water, and $22 \mu \mathrm{l}$ of $\mathrm{FeCl}_{2}(2 \mathrm{mM})$ in distilled water were mixed, and incubated for $10 \mathrm{~min}$ at room temperature. To the reaction mixture, $44 \mu 1$ of ferrozine $(5 \mathrm{mM})$ was added, and incubated for $10 \mathrm{~min}$ at room temperature, and then the absorbance of the reaction mixture at $540 \mathrm{~nm}$ was measured. Chelating activities of samples on $\mathrm{Fe}^{2+}$ was calculated by following equation: Chelating activity $(\%)=(\mathrm{A}-\mathrm{B}) / \mathrm{A} \times 100$, where $\mathrm{A}$ was absorbance of control reaction mixture without sample, and B was absorbance of test sample. 
Hydrogen peroxide $\left(\mathrm{H}_{2} \mathrm{O}_{2}\right)$ scavenging activities of ascophyllan and fucoidan were determined by spectrophotometoric method (U-1900 ratio beam spectrophotometer, Hitachi High-Technologies, Tokyo, Japan). To varying concentrations of sample solutions in distilled water, $\mathrm{H}_{2} \mathrm{O}_{2}$ solution in distilled water (final $5 \mathrm{mM}$ ) was added. After mixing, the absorbance of the reaction mixture at $230 \mathrm{~nm}$ was measured immediately for 2 min. Relative level of $\mathrm{H}_{2} \mathrm{O}_{2}$ in the reaction mixture was calculated by following equation: Relative level of $\mathrm{H}_{2} \mathrm{O}_{2}(\%)=\mathrm{A} / \mathrm{B} \mathrm{x}$ 100, where A was absorbance of the test sample, and B was the absorbance of the control reaction mixture without sample. To confirm the specificity of the assay system for $\mathrm{H}_{2} \mathrm{O}_{2}$, the effect of catalase was examined. In the assay, instead of sample solution, catalase solution (final 5 20 units/ml in distilled water) was added to hydrogen peroxide solution.

\subsection{Hydroxyl radical scavenging activity}

In addition to the Fenton reaction, it is also known that direct ultraviolet (UV) radiation on hydrogen peroxide results in hydroxyl radical generation [29]. In this study, we used the UV-radiation method as a hydroxyl radical generation system. A reaction mixture consisting of $20 \mu \mathrm{l}$ of hydrogen peroxide $(20 \mathrm{mM})$ in distilled water, $20 \mu \mathrm{l}$ of DMPO $(8.9 \mathrm{mM})$ in distilled water, and $40 \mu \mathrm{l}$ of sample solution in distilled water or solvent alone was exposed to UV radiation at $254 \mathrm{~nm}$ at $4.9 \mathrm{~W}$ for 2 min with a GL-15 UV lamp (UVC, Toshiba, Tokyo, Japan). Then the spectrum of DMPO-OH spin-adduct formed in each reaction mixture was measured by electron spin resonance (ESR) spectrometry. Measurement conditions of ESR (The EMX Plus, Bruker, Billerica, Massachusetts, USA) were as follows; field sweep: 3,327 - 3,412 G, field modulation frequency: $100 \mathrm{kHz}$, modulation amplitude: $3 \mathrm{G}$, sweep time: $122.880 \mathrm{~s}$, time constant: $163.840 \mathrm{~ms}$, microwave frequency: $9.458 \mathrm{GHz}$, microwave power: $4 \mathrm{~mW}$. The effect of D-mannitol as a well-known hydroxyl radical scavenger was also examined. In the assay, 
instead of a sample solution, $40 \mu \mathrm{l}$ of D-mannitol solution (20 2,000 $\mu \mathrm{g} / \mathrm{ml}$ in distilled water) was added to the reaction mixture. The extent of hydroxyl radical scavenging effect of each sample was calculated by the following equation. Scavenging effect $(\%)=\left(\mathrm{H}_{\text {control }}{ }^{-}\right.$ $\mathrm{H}_{\text {sample }} / \mathrm{H}_{\text {control }} \mathrm{X} 100$ in which, $\mathrm{H}_{\text {control }}$ and $\mathrm{H}_{\text {sample }}$ were the amplitudes of the second peak of DMPO-OH adduct in ESR spectrum for samples and control, respectively.

\subsection{Reducing power}

Reducing powers of polysaccharide samples were analyzed by the method described by Yen and Chen with slight modification [30]. In brief, $50 \mu \mathrm{l}$ of sample solution in distilled water was mixed with $50 \mu \mathrm{l}$ of potassium ferricyanide $\left(1 \%\right.$, w/v), and incubated at $37^{\circ} \mathrm{C}$ for $60 \mathrm{~min}$. The reaction was terminated by the addition of $25 \mu$ of trichloroacetic acid (TCA) solution (10\%, w/v) to the reaction mixture. The solution was then mixed with $25 \mu \mathrm{l}$ of ferric chloride (III) $(0.1 \%, w / v)$ solution, and the absorbance at $700 \mathrm{~nm}$ was measured. Vitamin $\mathrm{C}$ was used as a standard reducing agent. In the assay, instead of sample solutions, $50 \mu \mathrm{l}$ of vitamin C solution (0 200 $\mu \mathrm{g} / \mathrm{ml}$ in distilled water) was added to the reaction mixture. The reducing powers of polysaccharide samples were also confirmed by Fehling’s test [31].

\subsection{Statistical analysis}

All the experiments were repeated at least three times. Data were expressed as means \pm standard deviation (S.D.). Tested groups were compared with appropriate controls using Dunnett's multiple comparison test. Differences were considered significant at $P<0.05$ or $P<$ 0.01

\section{Results and discussion}




\subsection{Superoxide radical scavenging activities of ascophyllan and fucoidan}

The superoxide-scavenging activity of ascophyllan was examined by a luminol analog L-012-dependent chemiluminescence (CL) method. In this assay, hypoxanthine (HPX)-xanthine oxidase (XOD) system was used as a source of superoxide. As shown in Fig. 1A, when the initiation solution containing L-012 and HPX was added to the reaction mixture containing XOD, an immediate CL response was induced. Since the CL response was disappeared in the presence of $100 \mathrm{U} / \mathrm{ml}$ of SOD, it was confirmed that the CL response was mainly due to superoxide [32]. Ascophyllan at $100 \mu \mathrm{g} / \mathrm{ml}$ partially inhibited the CL response, and complete inhibition was attained at 1,000 $\mu \mathrm{g} / \mathrm{ml}$ (Fig. 1A). However, even a slight increase in CL response was observed in the presence of $10 \mu \mathrm{g} / \mathrm{ml}$ of ascophyllan rather than the scavenging effect. Fucoidan from F. vesiculosus also showed superoxide-scavenging activity, but the activity was obviously lower than ascophyllan (Fig. 1B). Although fucoidan at 1,000 $\mu \mathrm{g} / \mathrm{ml}$ showed significant superoxide-scavenging activity, increased CL-response was observed at $100 \mu \mathrm{g} / \mathrm{ml}$ as well as at $10 \mu \mathrm{g} / \mathrm{ml}$. At the present, the exact underlying mechanism responsible for the enhanced CL responses caused by ascophyllan and fucoidan at low concentration is still unclear, such enhancement effects of the polysaccharides were diminished after EDTA-treatment (Fig. 2). Both EDTA-treated polysaccharides showed increased superoxide scavenging activities as compared to EDTA-untreated ones. These results suggest that metal ions such as ferrous ions, which might be inherently existed in the polysaccharides, may involve in the slight increase in superoxide-mediated CL responses in the presence of low concentration of these polysaccharides. Based on these results, it is obvious that ascophyllan can exhibit a direct superoxide-scavenging activity, and more importantly the activity was even greater than that of fucoidan. Probably, certain structural features specific to ascophyllan may be responsible for the activity.

\subsection{Levels of metal ions in ascophyllan and fucoidan}


Since the presence of metal ions in the polysaccharides was suggested, metal element contents in ascophyllan and fucoidan were determined by ICP-OES. The detected metal element contents in these polysaccharides are listed in Table 2. The highest content of magnesium (Mg), $3.43 \mathrm{mg} / \mathrm{g}$ was found in ascophyllan, and the level is much higher than in fucoidan. Interestingly, both polysaccharides had almost same levels of iron (0.458 0.489 $\mathrm{mg} / \mathrm{g}$ ) as one of the major metal elements. The level of iron in fucoidan was even the highest among the metal elements detected. These results are especially important, since ferrous ions are considered to be a potent effective pro-oxidant, and is capable of catalyzing oxidative changes in biological molecules such as lipids, proteins, and other cellular components [33, 34]. Thus, one can speculate that ferrous ions existing in ascophyllan and fucoidan molecules may somehow involve in the increase in the superoxide-mediated CL-responses apart from the radical scavenging property of their own polysaccharide structure. Lower levels of $\mathrm{Ni}, \mathrm{Zn}$, and Mn were also detected in these polysaccharides with different content profiles, and $\mathrm{Cr}$ and Mo were detected only in fucoidan. Since simple dialysis against distilled water could not remove these metal elements (data not shown) from the polysaccharides, it was suggested that these polysaccharides form relatively tight conjugates with the metal ions through the chelating ability.

By the treatment with EDTA and subsequent dialysis, most of these metal elements except Mg were removed from ascophyllan and fucoidan. Especially more than $90 \%$ of ferrous ions were removed from the polysaccharides by this treatment (Table 2).

\subsection{Chelating effects of ascophyllan and fucoidan on ferrous ions $\left(\mathrm{Fe}^{2+}\right)$}

Our metal element analysis indicated that ascophyllan and fucoidan naturally contain certain levels of ferrous ions. Regarding hydroxyl radical scavenging mechanism of some compounds, it has been reported that the scavenging activity was not due to the direct scavenging action but inhibition of hydroxyl radical formation by chelating iron ions in the reaction system [35]. For example, it was reported that molecules that can inhibit hydroxyl radical-mediated deoxyribose 
degradation are those that can chelate iron ions and inhibit the Fenton reaction [34]. Hence, possible chelation of $\mathrm{Fe}^{2+}$ by ascophyllan and fucoidan was estimated by the method of Decker and Welch [28]. As shown in Fig. 3, EDTA-treated ascophyllan and fucoidan exhibited dose-dependent ferrous ion chelating ability, and the capacity of fucoidan was more pronounced than that of ascophyllan. As expected, ferrous chelating abilities of EDTA-untreated polysaccharides were much lower than those of the treated ones, and weak chelating effects of ascophyllan and fucoidan before EDTA-treated were observed only at 1,000 $\mu \mathrm{g} / \mathrm{ml}$ with $8.2 \%$ and $15.0 \%$, respectively. These results suggest that the chelating abilities of the polysaccharides toward ferrous ions can differ depending on the original ferrous levels in the polysaccharide molecules, which might vary even during the preparation processes.

Regarding chelating effect of sulfated polysaccharides on ferrous ions, it has been reported that all the sulfated polysaccharide fractions including typical fucoidan isolated from Laminaria japonica and Sargassum filipendula showed obvious chelating effect [36, 37]. It has also been reported that fucoidan oligosaccharides with average molecular weight of about 5,000 exhibited a potent chelating activity on $\mathrm{Fe}^{2+}$ [38]. Thus, it seems that ferrous chelating ability is a common chemical feature of sulfated polysaccharides.

\subsection{Hydrogen peroxide scavenging activities of ascophyllan and fucoidan}

Next, we examined the reactivity of ascophyllan and fucoidan on hydrogen peroxide. Hydrogen peroxide is not a free radical, but it is cell-membrane permeable, and has potential to cause significant toxic effect on cells. In addition, it can react with $\mathrm{Fe}^{2+}$ to form highly reactive hydroxyl radical by the Fenton reaction as mentioned above. As shown in Fig. 4, no significant scavenging effect of ascophyllan and fucoidan $(1,000 \mu \mathrm{g} / \mathrm{ml})$ toward hydrogen peroxide was observed. EDTA-treated polysaccharides also had no effect on hydrogen peroxide (date no shown). 


\subsection{Hydroxyl radical scavenging activities of ascophyllan and fucoidan}

Hydroxyl radical is the most reactive oxygen radical of all the ROS, and can react with adjacent various biological molecules, particularly lipids and nucleic acids [39, 40]. Although there are several methods for the detection of hydroxyl radical such as spectrophotometoric or colorimetric methods, ESR method is known as the most reliable assay for the direct detection of this radical species. The Fenton reaction often has been used as a hydroxyl radical generation system, in which $\mathrm{Fe}^{2+}$ and hydrogen peroxide are reacted to produce hydroxyl radical. It is also known that ultraviolet (UV) radiation directed on hydrogen peroxide results in hydroxyl radical generation [29]. Since we found that ascophyllan and fucoidan have chelating ability on iron ions, it is supposed that the iron-chelating activity might be partly responsible for hydroxyl radical scavenging activity when the Fenton reaction was used. To examine the direct scavenging activity of ascophyllan and fucoidan on hydroxyl radical, we applied the UV radiation method as a hydroxyl radical generation system. When spin-trapping agent DMPO was added to a hydrogen peroxide solution and subsequent UV radiation, the typical 1:2:2:1 ESR signal of the DMPO-OH adduct (an adduct from DMPO and hydroxyl radical) was observed. Fig. 5 shows the representative ESR spectra of DMPO-OH obtained by the addition of the solvent alone and various concentrations of ascophyllan and fucoidan $(10 \sim 1,000 \mu \mathrm{g} / \mathrm{ml})$ to the reaction mixture. In the presence of ascophyllan or fucoidan, the decreases in the height of the second peaks of the spectrum, which represent relative amount of DMPO-OH adduct, were observed, and the effects of the polysaccharides were concentration-dependent. These results clearly indicate that ascophyllan and fucoidan have direct scavenging ability toward hydroxyl radical. Both polysaccharides showed similar concentration-dependent profiles in terms of scavenging efficiency, which were nearly similar to those of D-mannitol at same concentration range (10 1,000 $\mu \mathrm{g} / \mathrm{ml})$ (Fig. 5). EDTA-treated asophyllan and fucoidan showed almost same hydroxyl radical scavenging activities as observed in untreated ones. Therefore, it is considered that these polysaccharides can exhibit direct hydroxyl radical-scavenging activity regardless of the levels of intramolecular iron or other metals. Fig. 6 shows the relationship 
between the concentrations of samples and the scavenging effects (\%). From these results, 50\% scavenging concentrations of EDTA-untreated and -treated ascophyllan and fucoidan were estimated to be 262.6, 222.4, 325.4, and $284.4 \mu \mathrm{g} / \mathrm{ml}$, respectively.

Regarding antioxidant activity of polysaccharides, there are few reports on the structure-antioxidant activity relationship of polysaccharides. The high uronic acid and sulfate content have been suggested to be advantageous for antioxidant activity of polysaccharide [41, 10]. Positive effect of contents of uronic acid on the antioxidant activity of polysaccahrides from mushroom (Pleurotus ostreatus) has also been reported [42]. Role of uronic acid in antioxidant activities of polysaccharides may also be supported by the finding that alginate oligosaccharides showed the strongest hydroxyl radical scavenging activity among alginate oligosaccharides, chitosan oligosaccharides, and fucoidan oligosaccharides with molecular weight of nearly 5,000 Da [38]. Based on these findings, one possible speculation is that uronic acids and sulfate groups in ascophyllan and fucoidan may partly responsible for the antioxidant activities. In addition, it was proposed that polysaccharides could inhibit the formation of hydroxyl radicals, probably due to the hydrogen or electron abstraction mechanism [43]. It was reported that the ease of abstraction of the anomeric hydrogen from the internal monosaccharide units made polysaccharides achieve the scavenging effect [44]. If this theory is applicable for the antioxidant activities of ascophyllan and fucoidan observed in this study, certain structural changes in these polysaccharides might occur after radical scavenging reactions. Further studies are obviously required to clarify such structural changes as well as the molecular basis of the radical scavenging activities of ascophyllan and fucoidan.

\subsection{Reducing power of ascophyllan and fucoidan}

Antioxidant activities of certain natural substances are correlated with the reducing power [45]. In general, reductones in reducing agents, which are capable of donating hydrogen atom, exert antioxidant activity via interrupting free radical chain reaction [46]. As shown in Fig. 7, ascophyllan and fucoidan exhibited the reducing power. In this assay, higher absorbance value 
means stronger reducing power of the samples. Both polysaccharides show considerable reducing power in a concentration-dependent manner. The activity of ascophyllan was stronger than that of fucoidan, and the reducing power of ascophyllan and fucoidan at $1,000 \mu \mathrm{g} / \mathrm{ml}$ were equivalent to 30 and $10 \mu \mathrm{g} / \mathrm{ml}$ of vitamin C, respectively. The stronger reducing power of ascophyllan than fucoidan was also confirmed by Fehling's test. Based on the approximate molecular weight of $400 \mathrm{kDa}$ for ascophyllan and $30 \mathrm{kDa}$ for fucoidan, the reducing powers of 1 mol of ascophyllan and fucoidan were estimated to be $18.63 \pm 1.97$ and $0.69 \pm 0.07 \mathrm{~mol}$ glucose equivalent, respectively. Similar to our results, reducing power of a sulfated polysaccharide isolated Sargassum filipendula at $500 \mu \mathrm{g} / \mathrm{ml}$ has been estimated to be equivalent to $100 \mu \mathrm{g} / \mathrm{ml}$ of vitamin C based on the same procedure used in this study [37]. Although the exact chemical background of the reducing powers of these polysaccharides is unclear now, polysaccharide chains have generally one reducing and multi non-reducing ends, and reducing end can contribute to the reducing power. Analysis of four sulfated polysaccharide fractions with different molecular weights prepared from Ulva pertusa Kjellm demonstrated that lower molecular weight polysaccharide fractions, in which higher number of reducing and non-reducing ends are existing, showed the stronger reducing power [47]. These findings suggest that molecular weight is a factor influencing the reducing power of polysaccharides. On the other hand, it has been reported that pectic acids known as polygalacturonic acid showed the extremely highest reducing power among the tested polysaccharides including chitosans and alginates with low and high molecular weights [48]. Hence, certain structural elements specific to the polysaccharides other than the molecular weight may be responsible for the reducing power. Further studies are required to clarify the origin of relatively high reducing power of ascophyllan.

\section{Conclusion}

The results clearly demonstrated that ascohyllan exhibits strong superoxide radical and hydroxyl radical scavenging activities, but hardly scavenges hydrogen peroxide. Althought the 
1 ability of ascophyllan to scavenge hydroxyl radical was similar to that of fucoidan, ascophyllan

2 showed stronger reducing power and superoxide radical scavenging activity than fucoidan.

3 Both polysaccharides could chelate $\mathrm{Fe}^{2+}$ with different extent, and the Fe-chelating efficiencies

4 of these polysaccharides varied depending on the inherently existed Fe levels in the

5 polysaccharides. Based on our results, it is concluded that ascophyllan can be used as a potent

6 natural antioxidant, as a food supplement, or in the pharmaceutical and medical field.

7

8

9

10

11

12

13

14

15

16

17

18

19

20

21

22

23

24

25 


\section{Table 1}

2 Operating conditions for ICP-OES

\begin{tabular}{ll}
\hline Parameter & Specification \\
\hline Power & $1,000 \mathrm{~W}$ \\
Plasma flow & $12.0 \mathrm{l} / \mathrm{min}$ \\
Auxiliary flow & $0 \mathrm{l} / \mathrm{min}$ \\
Sheath flow & $0.2 \mathrm{l} / \mathrm{min}$ \\
Nebuliser flow & $0.8 \mathrm{l} / \mathrm{min}$ \\
Nebuliser pressure & $3 \mathrm{bar}$ \\
Sample uptake rate & $1.0 \mathrm{ml} / \mathrm{min}$ \\
Rinse time & $30 \mathrm{sec}$ \\
\hline
\end{tabular}

3

4

5

6

7

8

9

10

11

12

13

14

15

16

17

18 
2 Metal elements ( $\mathrm{mg} / \mathrm{g}$ of sample) in EDTA-untreated and treated ascophyllan and fucoidan

\begin{tabular}{|c|c|c|c|c|}
\hline & \multicolumn{2}{|c|}{ Ascophyllan } & \multicolumn{2}{|c|}{ Fucoidan } \\
\hline & EDTA-untreated & EDTA-treated & EDTA-untreated & EDTA-treated \\
\hline $\mathrm{Mg}$ & 3.429 & $3.293(96.0)^{*}$ & 0.280 & $0.268(95.7)^{*}$ \\
\hline $\mathrm{Fe}$ & 0.458 & $0.024(5.2)^{*}$ & 0.489 & $\mathrm{ND}^{* *}(0) *$ \\
\hline $\mathrm{Ni}$ & 0.105 & $0.087(82.9) *$ & 0.085 & 0.072 (84.7)* \\
\hline $\mathrm{Zn}$ & 0.066 & $\mathrm{ND}^{* *}(0)^{*}$ & 0.090 & $\mathrm{ND}^{* *}(0)^{*}$ \\
\hline $\mathrm{Mn}$ & 0.031 & $0.001(3.2)^{*}$ & 0.100 & $0.002(2.0)^{*}$ \\
\hline $\mathrm{Ba}$ & 0.029 & $0.027(93.1)^{*}$ & 0.037 & 0.033 (89.2)* \\
\hline $\mathrm{Cr}$ & $\mathrm{ND}^{* *}$ & $\mathrm{ND}^{* *}$ & 0.201 & $\mathrm{ND}^{* *}(0)^{*}$ \\
\hline Mo & $\mathrm{ND}^{* *}$ & ND** & 0.016 & $\mathrm{ND}^{* *}(0)^{*}$ \\
\hline $\mathrm{Pb}$ & $\mathrm{ND}^{* *}$ & ND** & $\mathrm{ND}^{* *}$ & $\mathrm{ND}^{* *}$ \\
\hline $\mathrm{Cd}$ & $\mathrm{ND}^{* *}$ & ND** & $\mathrm{ND}^{* *}$ & ND** \\
\hline Co & $\mathrm{ND}^{* *}$ & ND** & $\mathrm{ND}^{* *}$ & $\mathrm{ND}^{* *}$ \\
\hline $\mathrm{Al}$ & $\mathrm{ND}^{* *}$ & $\mathrm{ND}^{* *}$ & $\mathrm{ND}^{* *}$ & $\mathrm{ND}^{* *}$ \\
\hline $\mathrm{V}$ & $\mathrm{ND}^{* *}$ & $\mathrm{ND}^{* *}$ & $\mathrm{ND}^{* *}$ & $\mathrm{ND}^{* *}$ \\
\hline $\mathrm{Cu}$ & ND** & $\mathrm{ND}^{* *}$ & $\mathrm{ND}^{* *}$ & $\mathrm{ND}^{* *}$ \\
\hline $\mathrm{Ti}$ & $\mathrm{ND}^{* *}$ & ND** & ND** & $\mathrm{ND}^{* *}$ \\
\hline
\end{tabular}

$3 *$ The values in parentheses indicate residual levels of metal elements after EDTA-treatment (\% of original

4 levels)

$5 \quad * * \mathrm{ND}$; not detectable

6

7

8

9

10

11

12

13

14

15

16 


\section{References}

[1] S.P. Hussain, L.J. Hofseth, C.C. Harris, Nature Reviews Cancer 3 (2003) 276-285.

[2] S. Reuter, S.C. Gupta, M.M. Chaturvedi, B.B. Aggarwal, Free Radical Biology and Medicine 49 (2010) 1603-1616.

[3] K.J. Barnham, C.L. Masters, A.I. Bush, Nature Reviews Drug Discovery 3 (2004) 205-214.

[4] C. Behl, J.B. Davis, R. Lesley, D. Schubert, Cell 77 (1994) 817-827.

[5] A. Ajithkumar, R. Andersson, M. Siika-aho, M. Tenkanen, P. Aman, Carbohydrate Polymers 64 (2006) 233-238.

[6] U. Surenjav, L. Zhang, X.J. Xu, X.F. Zhang, F.B. Zeng, Carbohydrate Polymers 63 (2006) 97-104.

[7] S. Hida, N. N. Miura, Y. Adachi, N. Ohno, Journal of Autoimmunity 25 (2005) 93-101.

[8] E.H. Han, J.H. Choi, Y.P. Hwang, H.J. Park, C.Y. Choi, Y.C. Chung, J.K. Seo, H.G. Jeong, Food and Chemical Toxicology 47 (2009) 62-69.

[9] Y.X. Sun, H.T. Liang, G.Z. Cai, S.W. Guan, H.B. Tong, X.D. Yang, J. Liu, International Journal of Biological Macromolecules 44 (2009) 14-17.

[10] H. Qi, Q. Zhang, T. Zhao, R. Chen, H. Zhang, X. Niu, Z. Li, International Journal of Biological Macromolecules 37 (2005) 195-199.

[11] D.G. Medcalf, B. Larsen, Carbohydrate Research 59 (1977) 531-537.

[12] M.S. Pereira, B. Mulloy, P.A.S. Mourão, Journal of Biological Chemistry 274 (1999) 7656-7667.

[13] S. Koyanagi, N. Tanigawa, H. Nakagawa, S. Soeda, H. Shimeno, Biochemical Pharmacology 65 (2003) 173-179.

[14] P. Karmaker, C.A. Pujol, E.B. Damonte, T. Ghosh, B. Ray, Carbohydrate Polymers 80 
(2010) 514-521.

[15] S. Sinha, A. Astani, T. Ghosh, P. Schnitzler, B. Ray, Phytochemistry 71 (2010) 235-242.

[16] A. Cumashi, N.A. Ushakova, M.E. Preobrazhenskaya, A. D’Incecco, A. Piccoli, L. Totani, N. Tinari, G.E. Morozevich, A.E. Berman, M.I. Bilan, A.I. Usov, N.E. Ustyuzhanina, A.A. Grachev, C.J. Sanderson, M. Kelly, G.A. Rabinovich, S. Iacobelli, N.E. Nifantiev, Glycobiology 17 (2007) 541-552.

[17] D.O. Croci, A. Cumashi, N.A. Ushakova, M.E. Preobrazhenskaya, A. Piccoli, L. Totani, N.E. Ustyuzhanina, M.I. Bilan, A.I. Usov, A.A. Grachev, G.E. Morozevich, A.E. Berman, C.J. Sanderson, M. Kelly, P. Di Gregorio, C. Rossi, N. Tinari, S. Iacobelli, G.A. Rabinovich, N.E. Nifantiev, PLoS ONE 6 (2011) e17283.

[18] H.R.B. Raghavendran, P. Srinivasan, S. Rekha, International Immunopharmacology 11 (2011) 157-163.

[19] E.J. Kim, S.Y. Park, J.Y. Lee, J.H. Park, BMC Gastroenterology 10 (2010) 96.

[20] J.O. Jin, M.G. Song, Y.N. Kim, J.I. Park, J.Y. Kwak, Molecular Carcinogenesis 49 (2010) 771-782.

[21] J. Wang, Q. Zhang, Z. Zhang, H. Song, P. Li, International Journal of Biological Macromolecules 46 (2010) 6-12.

[22] B. Larsen, A. Haug, T. Painter, Acta Chemica Scandinavica 24 (1970) 3339-3352.

[23] B. Kloareg, M. Demarty, S. Mabeau, International Journal of Biological Macromolecules 8 (1986) 380-386.

[24] S. Nakayasu, R. Soegima, K. Yamaguchi, T. Oda, Bioscience Biotechnology and Biochemistry 73 (2009) 961-964.

[25] Z. Jiang, T. Okimura, T. Yokose, Y. Yamasaki, K. Yamaguchi, T. Oda, Journal of Bioscience and Bioengineering, 110 (2010) 113-117. 
1 [26] Z. Jiang, T. Okimura, K. Yamaguchi, T. Oda, Nitric Oxide 25 (2011) 407-415.

[27] K. Kadomura, T. Nakashima, M. Kurachi, K. Yamaguchi, T. Oda, Fish and Shellfish Immunology 21 (2006) 209-214.

[28] E.A. Decker, B. Welch, Journal of Agricultural and Food Chemistry 38 (1990) 674-677.

[29] K. Anzai, T. Aikawa, Y. Furukawa, Y. Matsushima, S. Urano, T. Ozawa, Archives of Biochemistry and Biophysics 415 (2003) 251-256.

[30] G.C. Yen, H.Y. Chen, Journal of Agricultural and Food Chemistry 43 (1995) 27-32.

[31] J.K.N. Jones, R.J. Stoodley, Methods in Carbohydrate Chemistry 5 (1965) 36-38.

[32] M. Ueno, T. Hiroki, S. Takeshita, Z. Jiang, D. Kim, K. Yamaguchi, T. Oda, Carbohydrate Research 352 (2012) 88-93.

[33] H.O. Hultin, in: A.J. Angelo (ed.), Lipid Oxidation in Muscle foods via Redox Iron. Lipid oxidation in food, American Chemical Society, Washington, 1992, pp.105-113.

[34] C. Smith, B. Halliwell, O.I. Aruoma, Food and Chemical Toxicology 30 (1992) 483-489.

[35] M.Y. Shon, T.H. Kim, N.J. Sung, Food Chemistry 82 (2003) 593-597.

[36] J. Wang, Q. Zhang, Z, Zhang, Z. Li, International Journal of Biological Macromolecules 42 (2008) 127-132.

[37] L.S. Costa, G.P. Fidelis, C.B.S. Telles, N. Dantas-Santos, R.B.G. Camara, S.L. Cordeiro, M.S.S.P. Costa, J. Almeida-Lima, R.F. Melo-Silveira, R.M. Oliveira, I.R.L. Albuquerque, G.P.V. Andrade, H.A.O. Rocha, Marine Drugs 9 (2011) 952-966.

[38] P. Wang, X. Jiang, Y. Jiang, X. Hu, H. Mou, M. Li, H. Guan, Natural Product Research 21 (2007) 646-654.

[39] M. Martinez-Caynela, Biochimie 77 (1995) 147-161.

[40] F.C. Cheng, J.F. Jen, T.H. Tsai, Journal of Chromatography B 781 (2002) 481-496.

[41] H. Chen, M. Zhang, B. Xie, Journal of Agricultural and Food Chemistry 52 (2004) 
3333-3336.

2 [42] Y. Zhang, L. Dai, X. Kong, L. Chen, International Journal of Biological Macromolecules 51 (2012) 259-265.

[43] H. Chen, Z. Wang, Z. Qu, L. Fu, P. Dong, X. Zhang, European Food Research and 5

[44] E. Tsiapali, S. Whaley, J. Kalbfleisch, H.E. Ensley, I.W. Browder, D.L. Williams, Free Radical Biology and Medicine 30 (2001) 393-402.

[45] P.D. Duh, P.C. Du, G.C. Yen, Food and Chemical Toxicology 37 (1990) 1055-1061.

9

[46] M.H. Gordon, in: B.J.F. Hudson (ed.), The Mechanism of Antioxidant Action in vitro. Food Antioxidants, Elsevier Applied Science, London and New York, 1990, pp.1-18.

[47] H. Qi, T. Zhao, Q. Zhang, Z. Li, Z. Zhao, R. Xing, Journal of Applied Phycology 17 (2005) 527-534.

[48] H. Tomida, T. Yasufuku, T. Fujii, Y. Kondo, T. Kai, M. Anraku, Carbohydrate Research 345 (2010) 82-86. 


\section{$1 \quad$ Figure legends}

2 Fig. 1. Superoxide scavenging activities of ascophyllan and fucoidan as measured by L-012-dependent chemiluminescence (CL) method. (A) CL-response patterns in the hypoxanthine (HPX)-xanthine oxidase (XOD) system in the presence of $0(\bigcirc), 10(\mathbf{O}), 100(\mathbf{\Delta})$, or 1,000 ( $\mathbf{\square}) \mu \mathrm{g} / \mathrm{ml}$ of ascophyllan. (B) CL-response patterns in the hypoxanthine (HPX)-xanthine oxidase (XOD) system in the presence of 0 $(\bigcirc), 10(\mathbf{O}), 100(\mathbf{\Delta})$, or 1,000 ( $\mathbf{\square}) \mu \mathrm{g} / \mathrm{ml}$ of fucoidan. Insets indicate the integrated CL-response intensity values calculated from the CL- responses during 600 sec. Each value represents the means \pm standard deviation of triplicate measurements. Asterisks indicate significant differences between with and without ascophyllan or fucoidan $\left({ }^{*} p<0.05\right.$, ${ }^{*} p<<$ $0.01)$.

Fig. 2. Superoxide scavenging activities of EDTA-treated ascophyllan and fucoidan as measured by L-012-dependent chemiluminescence (CL) method.

(A) CL-response patterns in the hypoxanthine (HPX)-xanthine oxidase (XOD) system in the presence of $0(\bigcirc), 10(\mathbf{O}), 100(\mathbf{\Delta})$, or 1,000 ( $\mathbf{\square}) \mu \mathrm{g} / \mathrm{ml}$ of EDTA-treated ascophyllan. (B) CL-response patterns in the hypoxanthine (HPX)-xanthine oxidase (XOD) system in the presence of $0(\bigcirc), 10(\mathbf{O}), 100(\mathbf{\Delta})$, or 1,000 ( $\mathbf{\square}) \mu \mathrm{g} / \mathrm{ml}$ of EDTA-treated fucoidan. Insets indicate the integrated CL-response intensity values calculated from the CL- responses during 600 sec. Each value represents the means \pm standard deviation of triplicate measurements. Asterisks indicate significant differences between with and without EDTA-treated ascophyllan

Fig. 3. Chelating activities of EDTA-treated and untreated ascophyllan and fucoidan on $\mathrm{Fe}^{2+}$. The values indicate $\mathrm{Fe}^{2+}$-chelating effects of EDTA-untreated $(\square)$ and treated $(\boldsymbol{\square})$ ascophyllan and fucoidan at the indicated concentrations as measured by the spectrophotometoric method as described in the text. Each value represents the means \pm standard deviation of triplicate measurements. Asterisks indicate significant differences between with or without 
polysaccharide samples $\left({ }^{*} p<0.05,{ }^{* *} p<0.01\right)$.

Fig. 4. Hydrogen peroxide scavenging activities of ascophyllan and fucoidan as measured by the spectrophotometoric method. After addition of catalase at $5(\boldsymbol{O}), 10(\mathbf{A})$, or $20 \mathrm{units} / \mathrm{ml}$ (ם), or $1,000 \mu \mathrm{g} / \mathrm{ml}$ of ascophyllan $(\bigcirc)$ or fucoidan $(\triangle)$ to assay system, relative levels of hydrogen peroxide were measured. Each value represents the means \pm standard deviation of triplicate measurements.

Fig. 5. Hydroxyl radical scavenging activities of ascophyllan and fucoidan as measured by the ESR-spin trapping method. Representative ESR spectra of DMPO-OH obtained by the direct UV-radiation on hydrogen peroxide in the presence of the indicated concentrations $(0,10,100$, or $1,000 \mu \mathrm{g} / \mathrm{ml}$ ) of mannitol (A), EDTA-treated ascophyllan (B), EDTA-untreated ascophyllan (C), EDTA-treated fucoidan (D), and EDTA-untreated fucoidan (E).

Fig. 6. Hydroxyl radical scavenging effects of ascophyllan and fucoidan as measured by the ESR-spin trapping method. After addition of varying concentrations of D-mannitol ( $\left.\square,--{ }_{-}\right)$, EDTA-untreated ascophyllan $(\bigcirc, \ldots$ _ $)$ or fucoidan $(\triangle$, _ _- $)$, or EDTA-treated ascophyllan $(\mathbf{O}, \ldots$ _ $)$ or fucoidan $(\mathbf{\Lambda}, \ldots \ldots$ _...) to assay system, ESR spectra of DMPO-OH adducts were measured, and scavenging effect (\%) of each sample versus sample concentration was plotted as described in the text. Each value represents the means \pm standard deviation of triplicate measurements.

Fig. 7. Reducing power of EDTA-treated and untreated ascophyllan and fucoidan. After addition of indicated concentrations of EDTA-untreated ascophyllan $(\bigcirc)$ or fucoidan $(\triangle)$, or EDTA-treated ascophyllan $(\mathbf{O})$ or fucoidan $(\boldsymbol{\Delta})$ to reaction mixture, absorbance at $700 \mathrm{~nm}$ was measured as described in the text. Each value represents the means \pm standard deviation of triplicate measurements. Inset indicates the values in the presence of the indicated concentrations of vitamin $\mathrm{C}$ as measured by the same procedure. 
1

Fig. 1

2

3

(A)

4

5

(B)
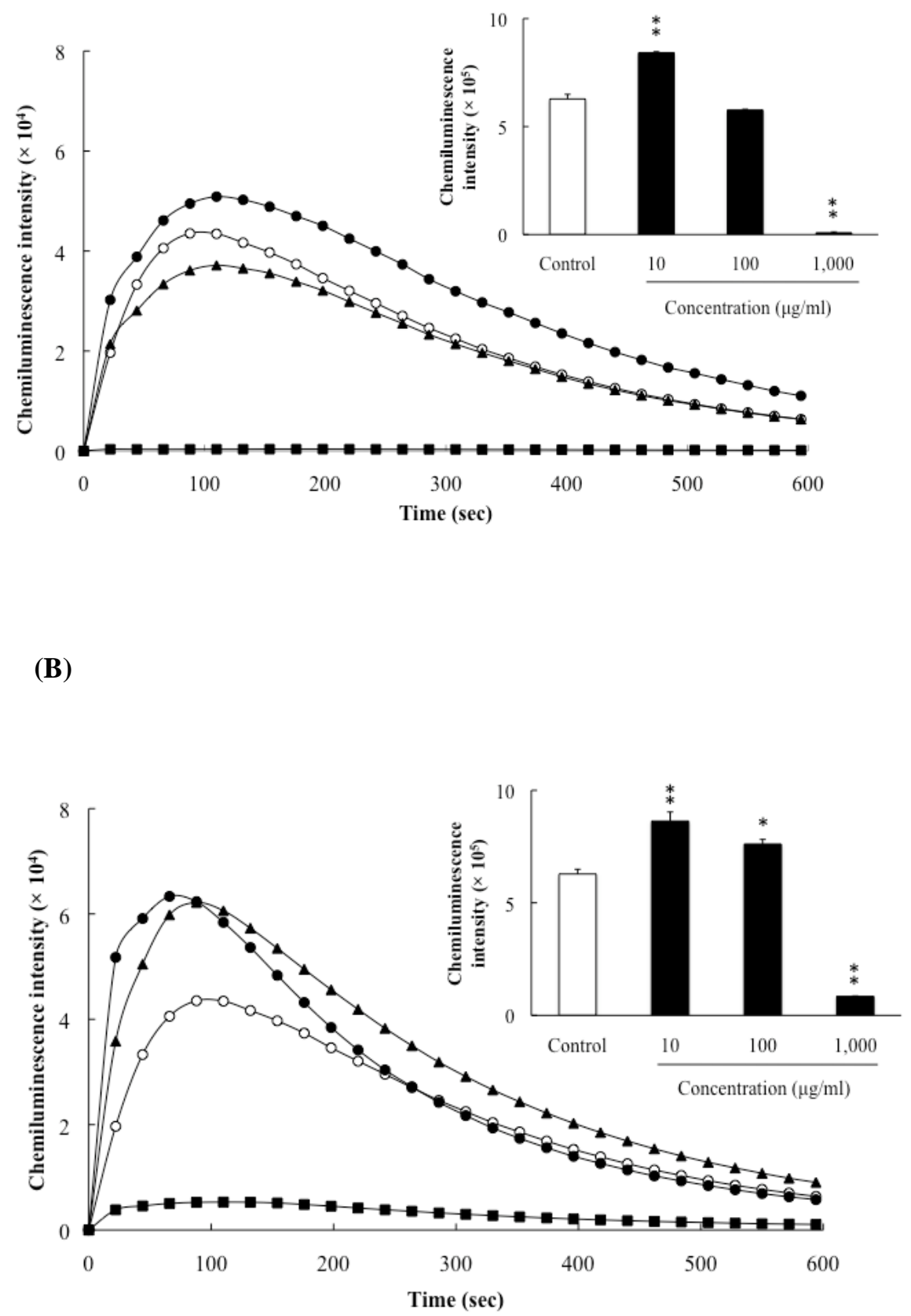
Fig. 2

2

3

(A)

4

5

6

7

8

9

10

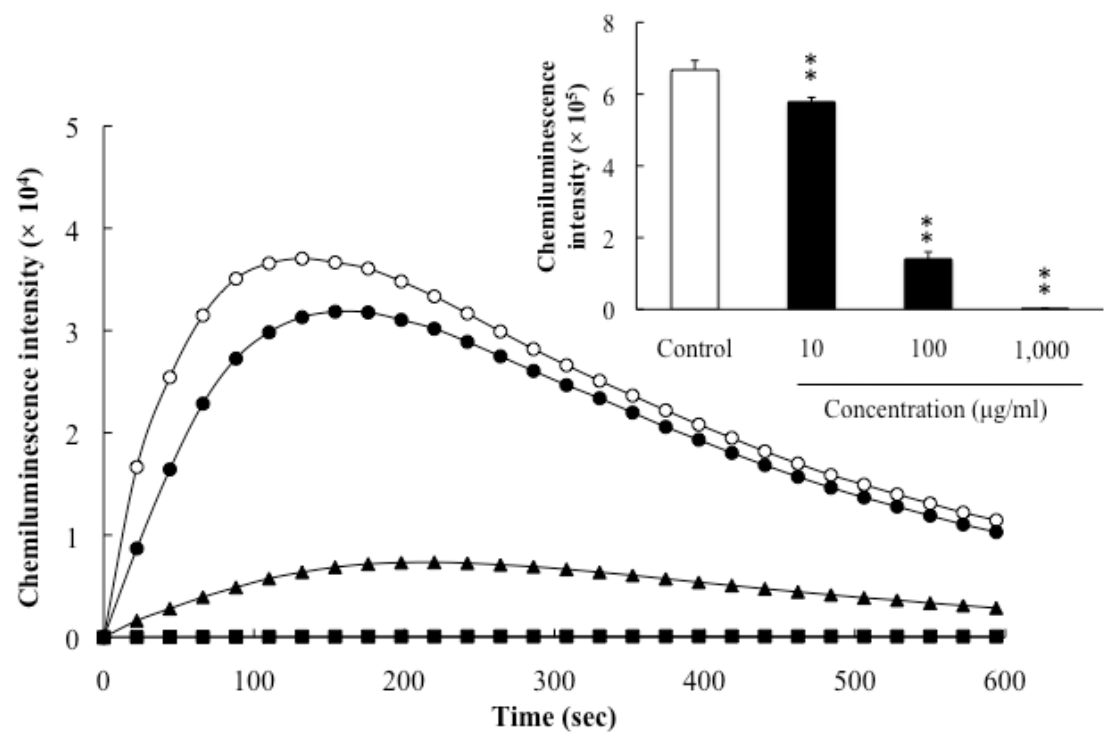

(B)

16

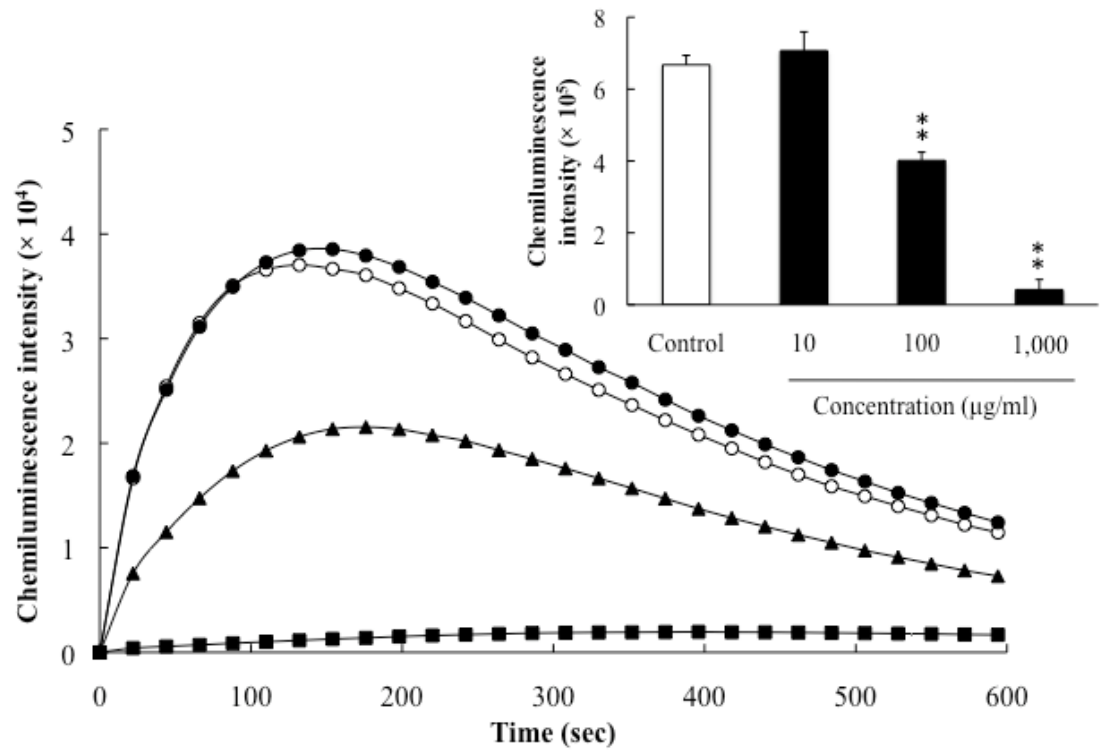


$1 \quad$ Fig. 3

2

3

4

5

6

7

8

9

10

11

12

13

14

15

16

17

18

19

20

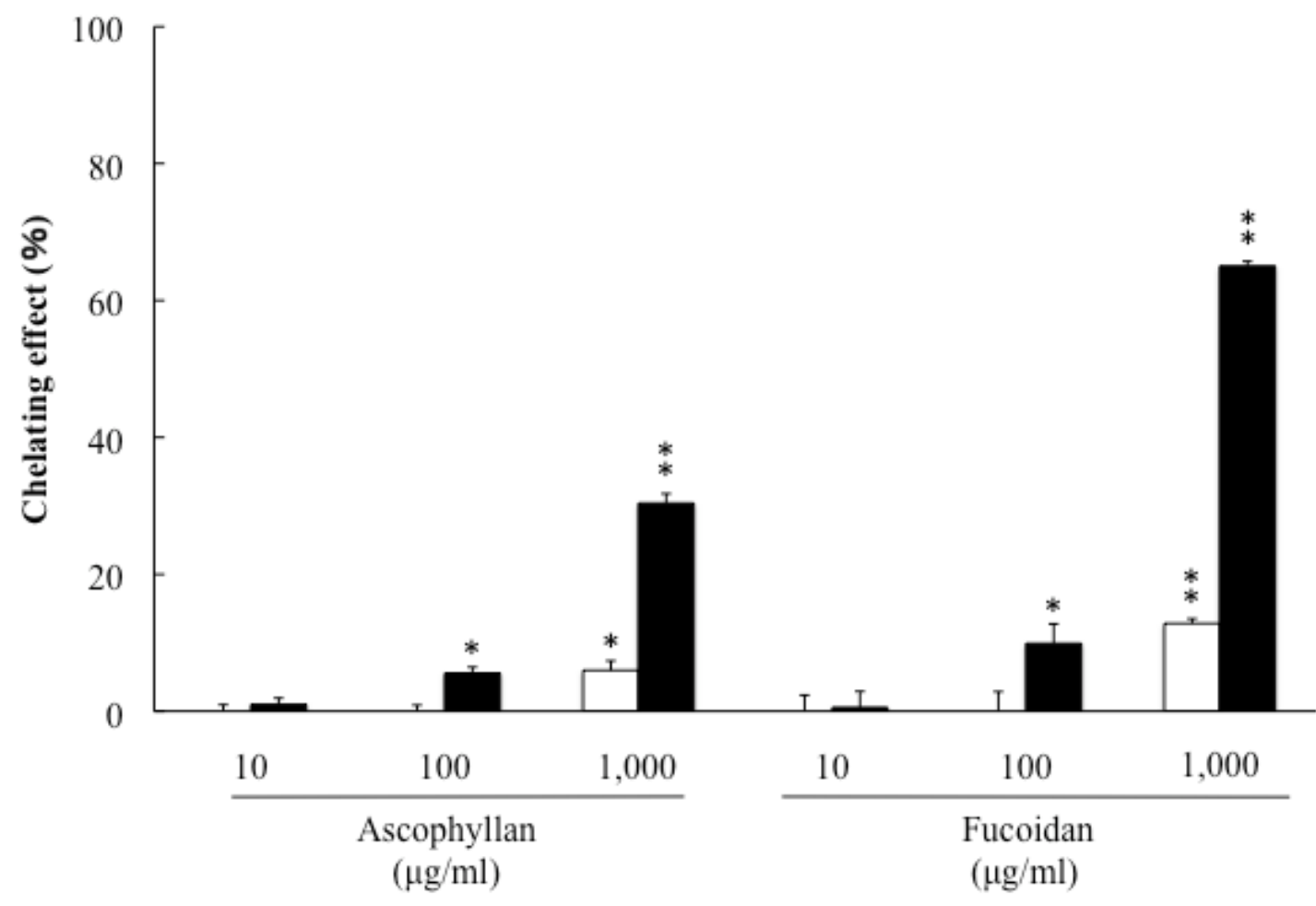

21

22

23

24

25

26

27

28 
1 Fig. 4

2

3

4

5

6

7

8

9

10

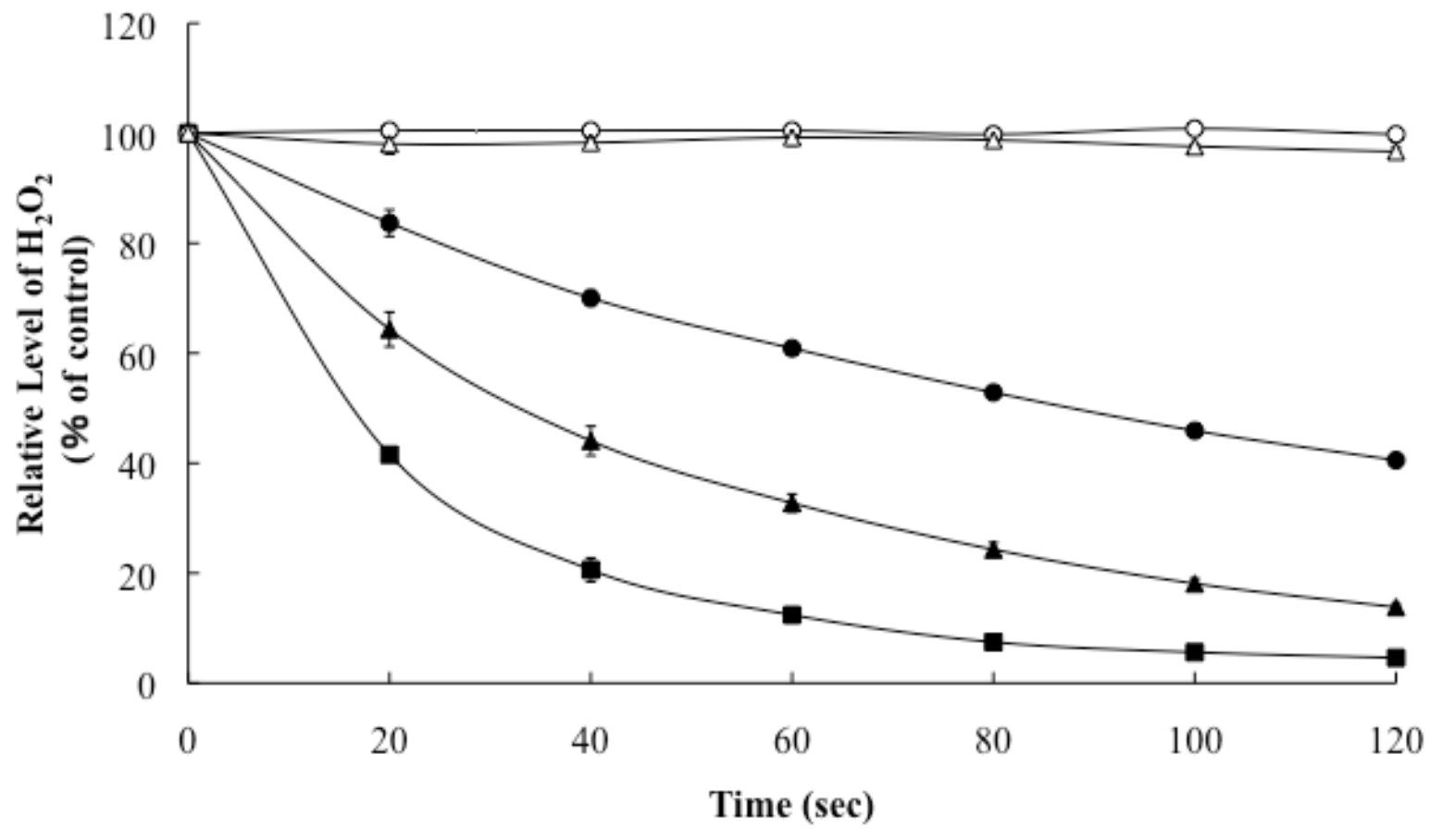

20

21 


\section{Fig. 5}

2

3

4

5

6

7 (A)

8

9

10

11

12

15

16

18

19

21

22

23

24

25

26

27

28
Control

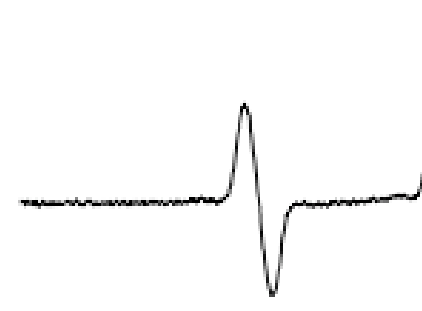

Mannitol

$10 \mu \mathrm{g} / \mathrm{ml}$
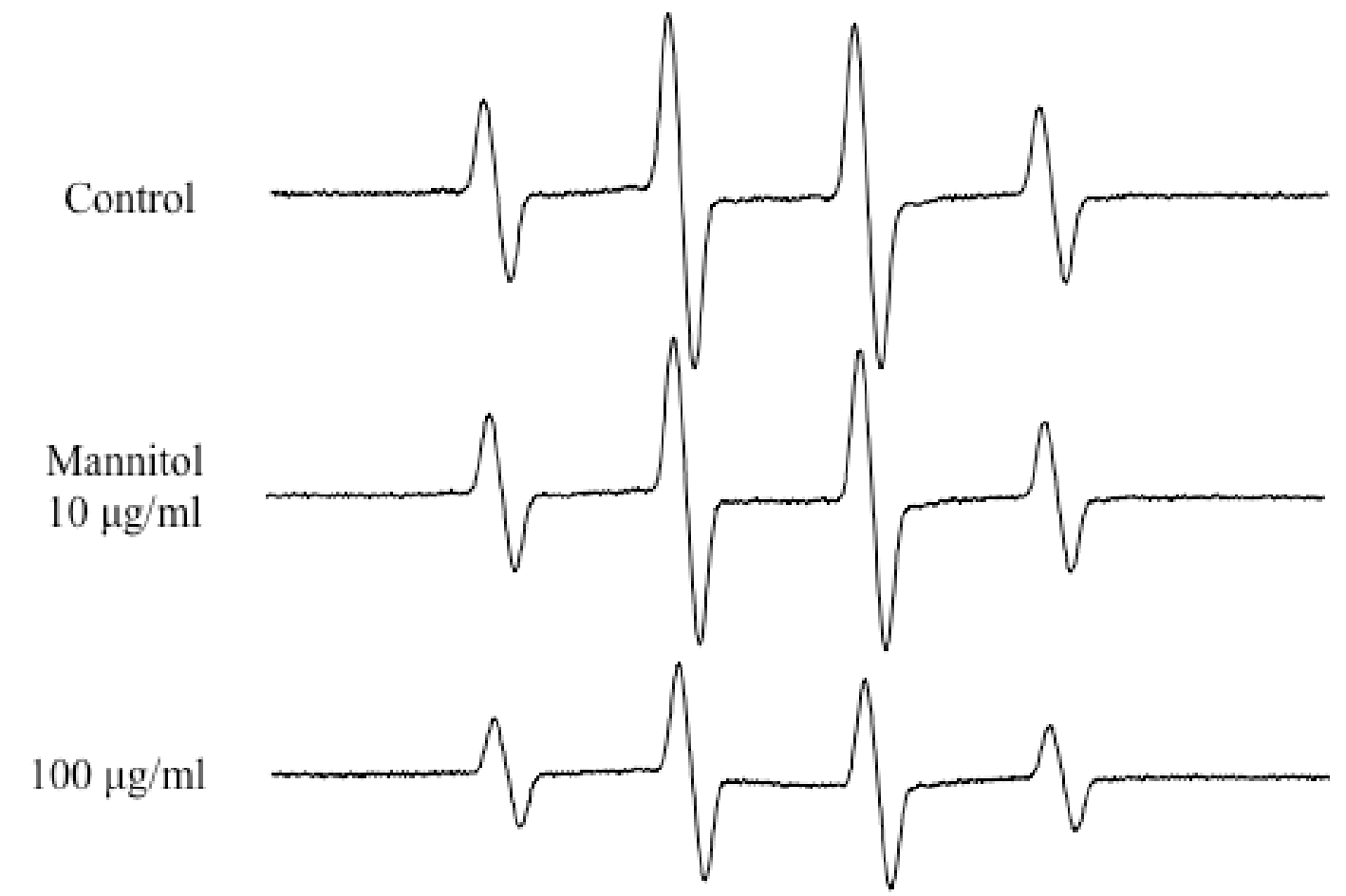

$$
1,000 \mu \mathrm{g} / \mathrm{ml}
$$


Fig. 5

2

3

4

5

$6 \quad$ (B)

7

8

9

10

11

14

15

16

18

EDTA

Ascophyllan

$10 \mu \mathrm{g} / \mathrm{ml}$

4

Control

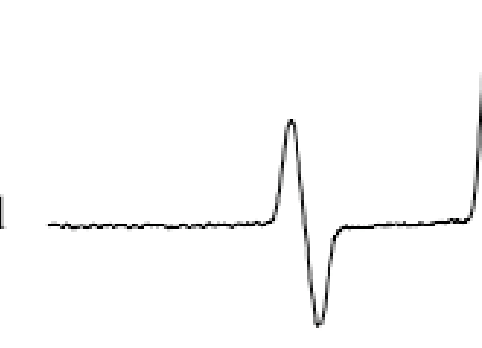

20

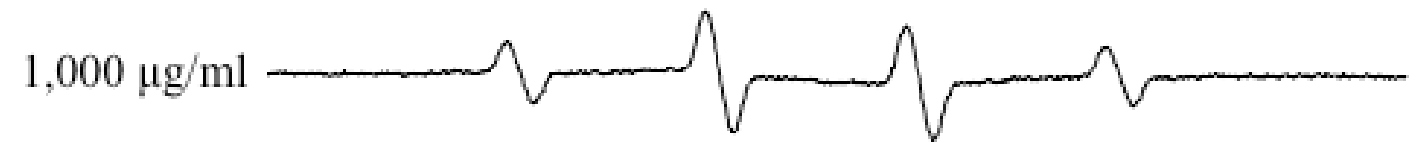

21

22

23

$100 \mu \mathrm{g} / \mathrm{ml}$

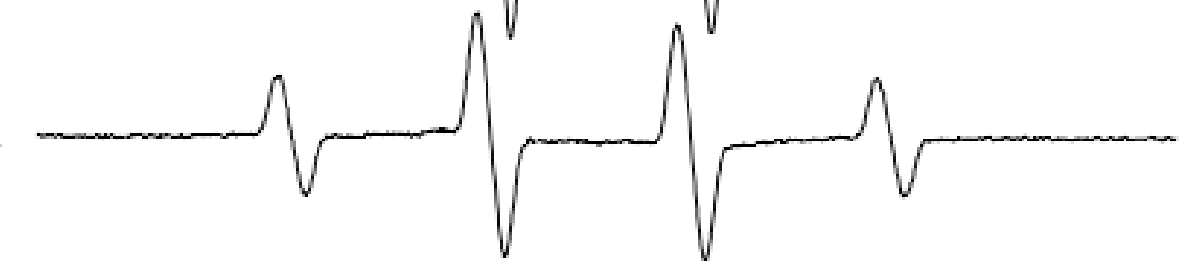

24

25

26

27

28 
1 Fig. 5

2

3

4

5

6

7 (C)

8

9

10

11

12

15

16

19
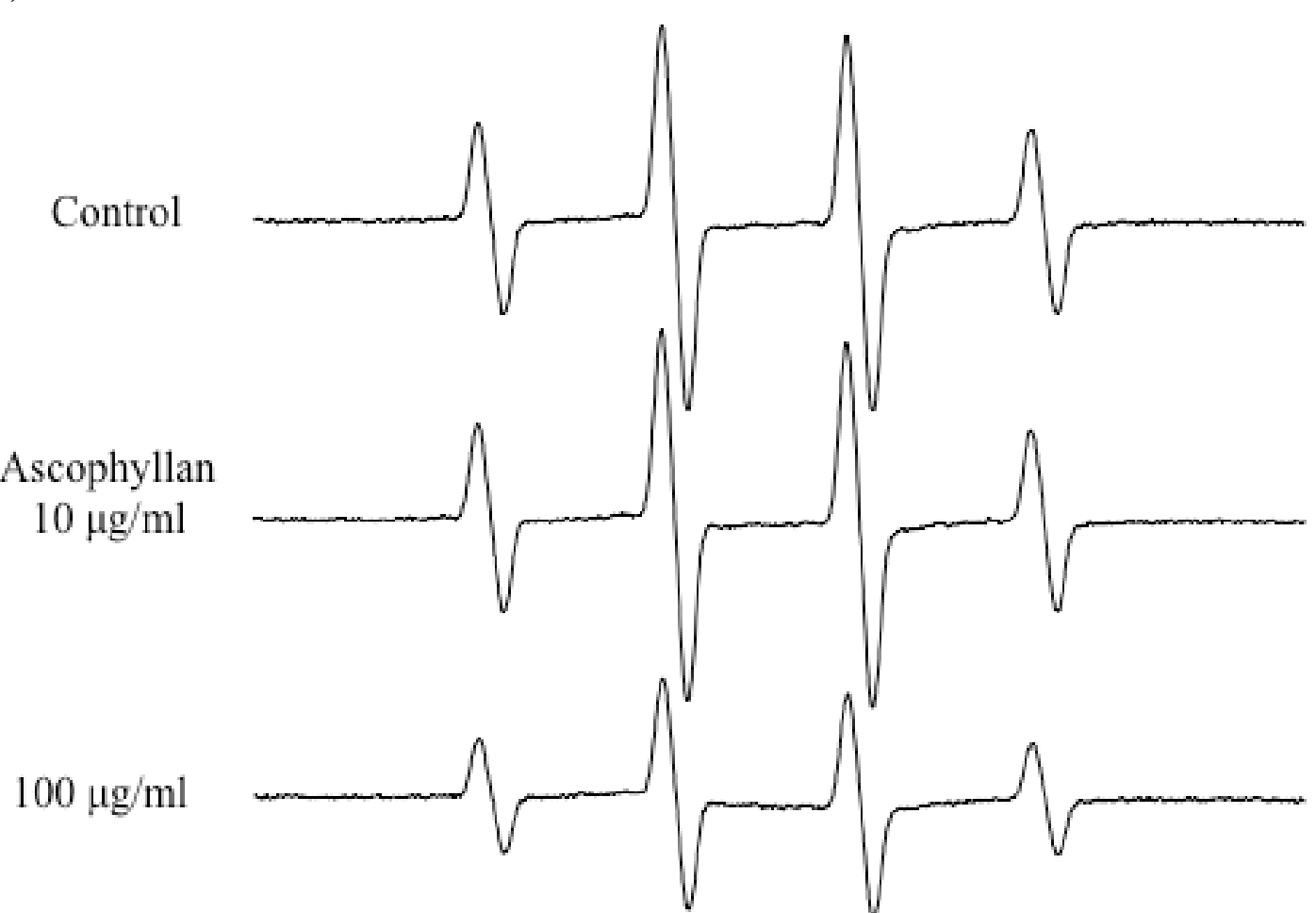

Ascophyllan

$10 \mu \mathrm{g} / \mathrm{ml}$

5

6

21
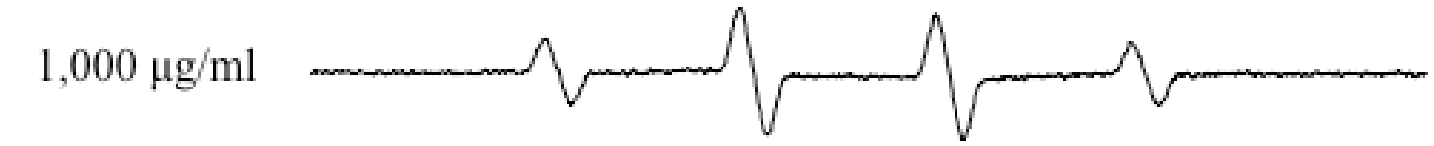

22

23

3,320

3,345

3,370

3,395

3,420

G 
Fig. 5

2

3

4

5

6

7 (D)

8

9

10

11

12

13

15

16

17

19

22

23

24

25

26

27

28

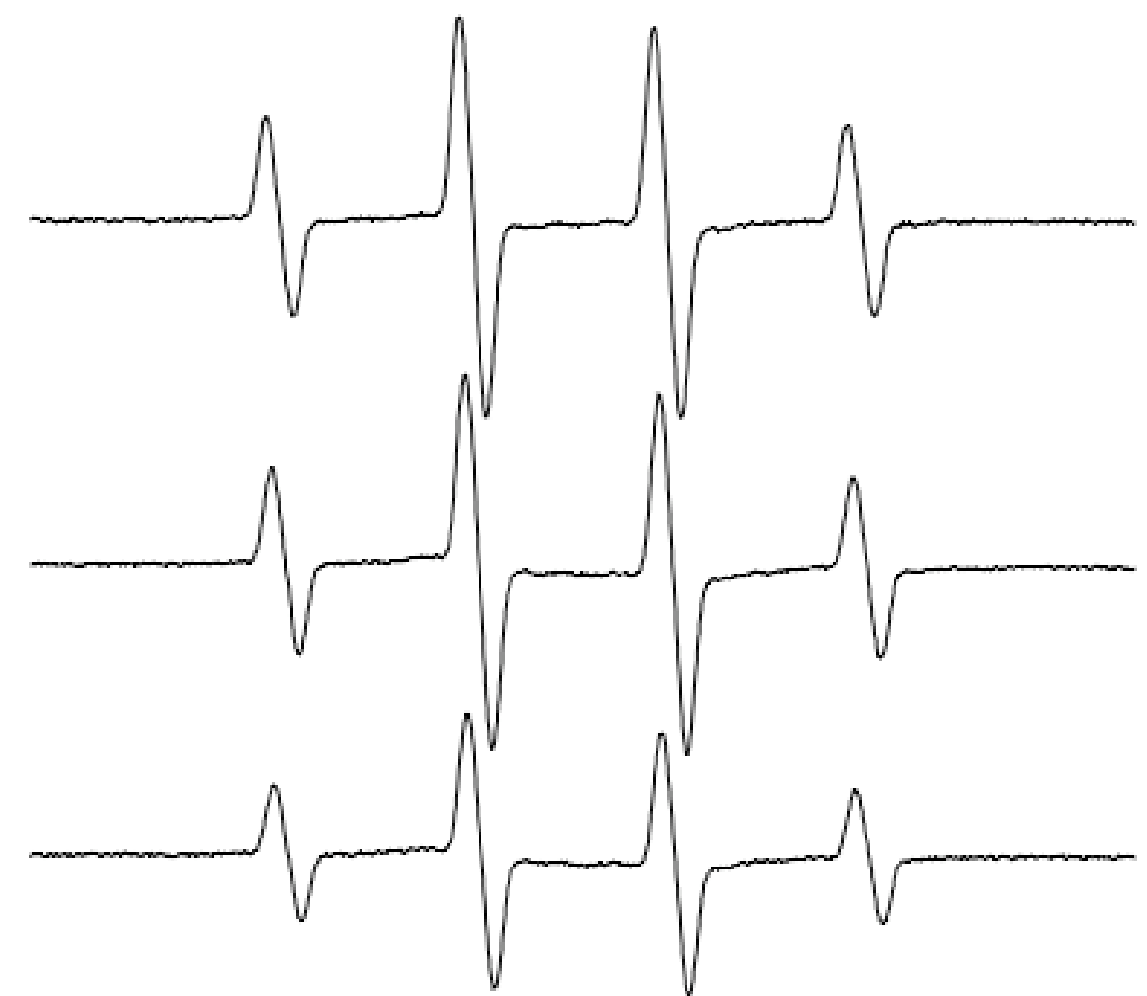

$1,000 \mu \mathrm{g} / \mathrm{ml}$

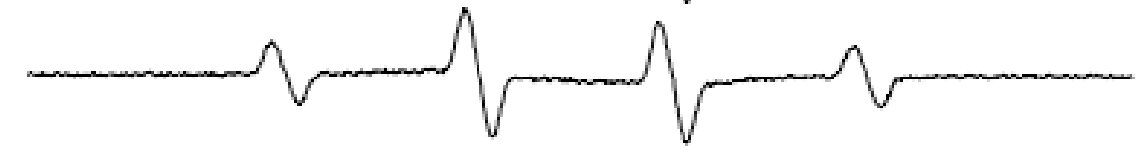

Control

EDTA

Fucoidan

$10 \mu \mathrm{g} / \mathrm{ml}$

$100 \mu \mathrm{g} / \mathrm{ml}$

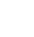

3

3,320

3,345

3,370

3,395

3,420

G 
Fig. 5

2

3

4

5

6

$7 \quad$ (E)

8

9

10

11

12

15

16

17

19

Fucoidan

$10 \mu \mathrm{g} / \mathrm{ml}$

5

Control

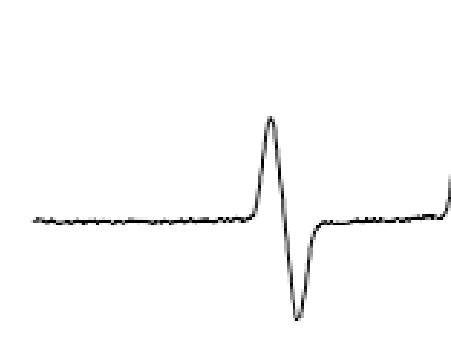

1
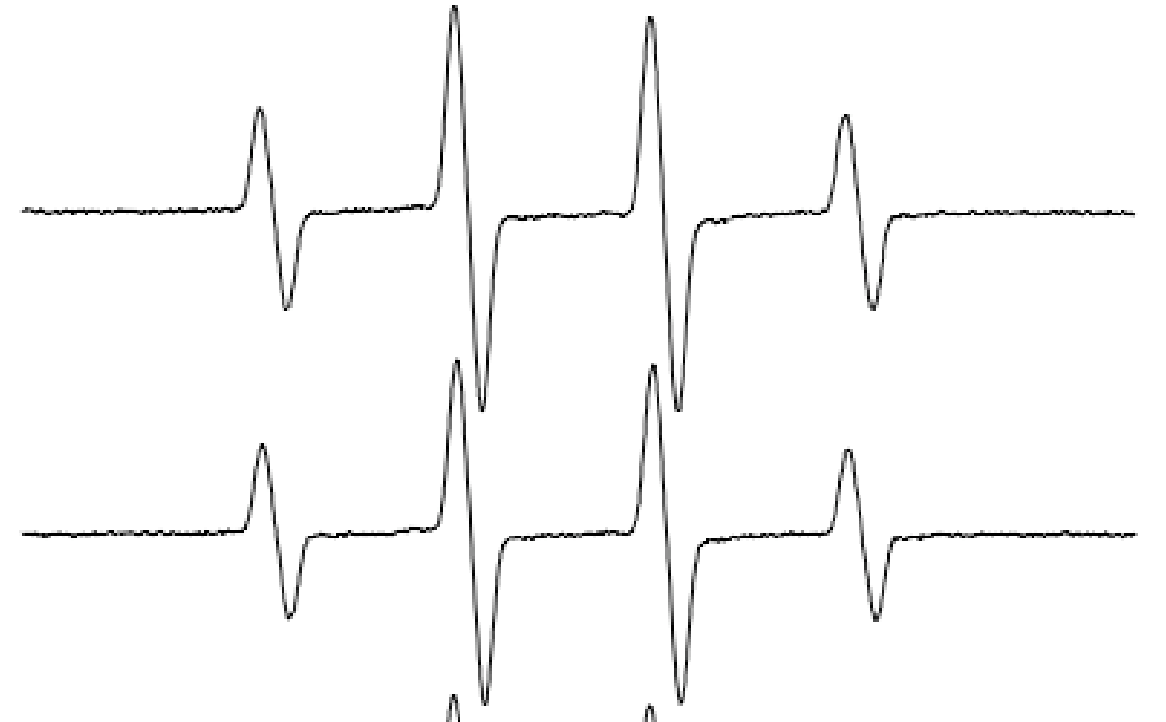

7

$100 \mu \mathrm{g} / \mathrm{ml}$
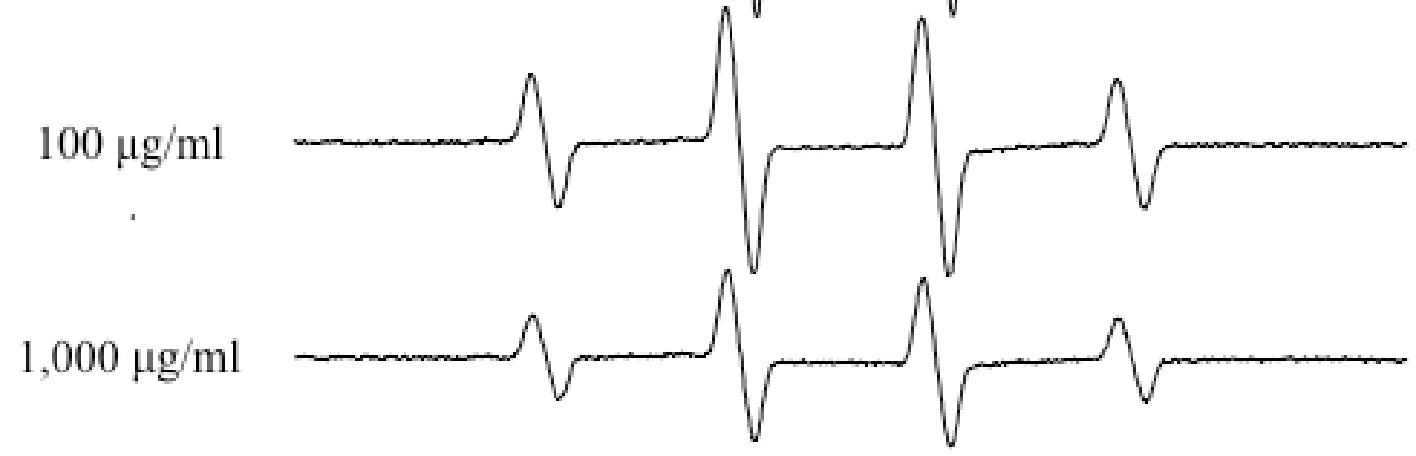

22

23

24

25

26

27

28 
$1 \quad$ Fig. 6

2

3

4

5

6

7

8

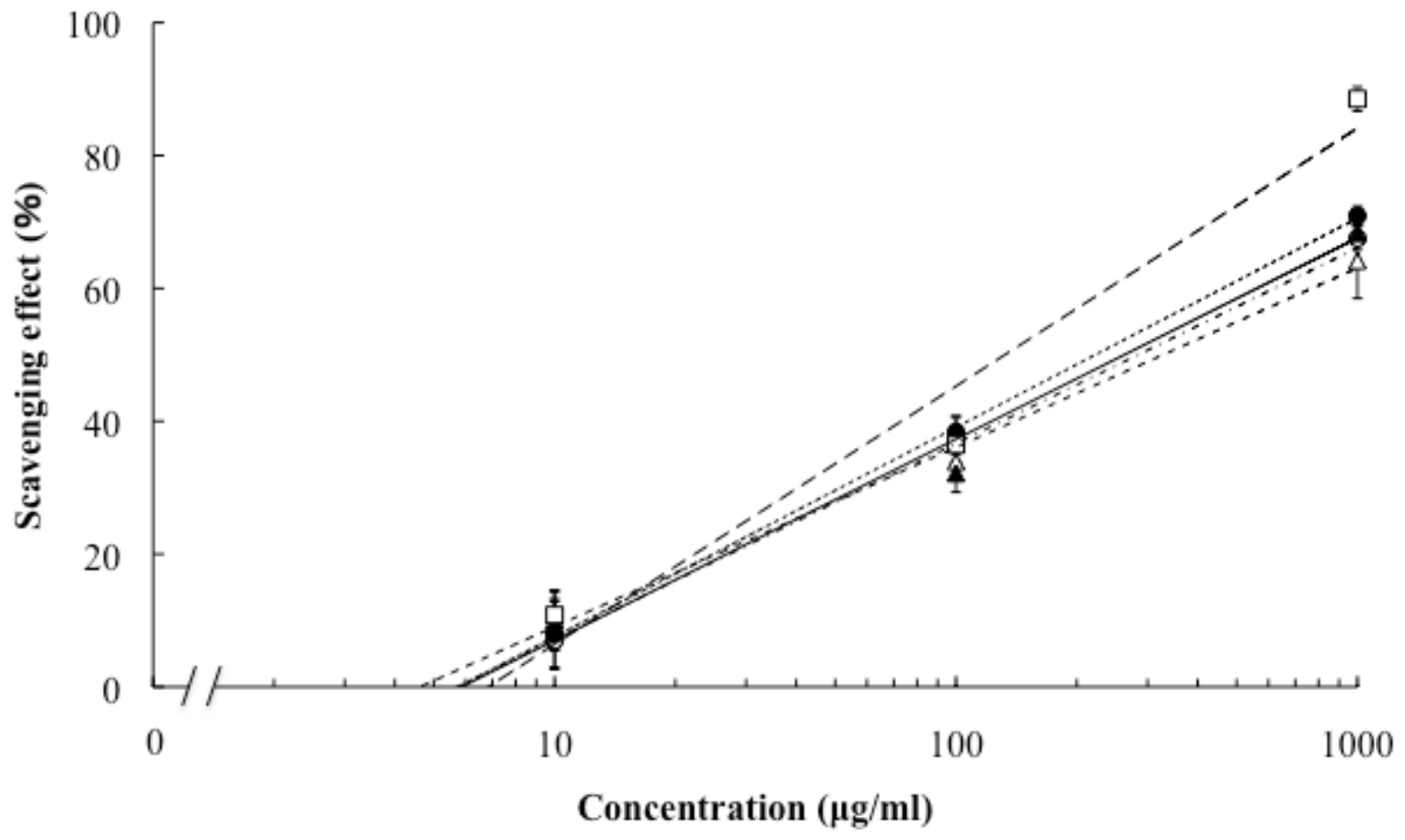

17 
1 Fig. 7

2

3

4

5

6

7

8

9

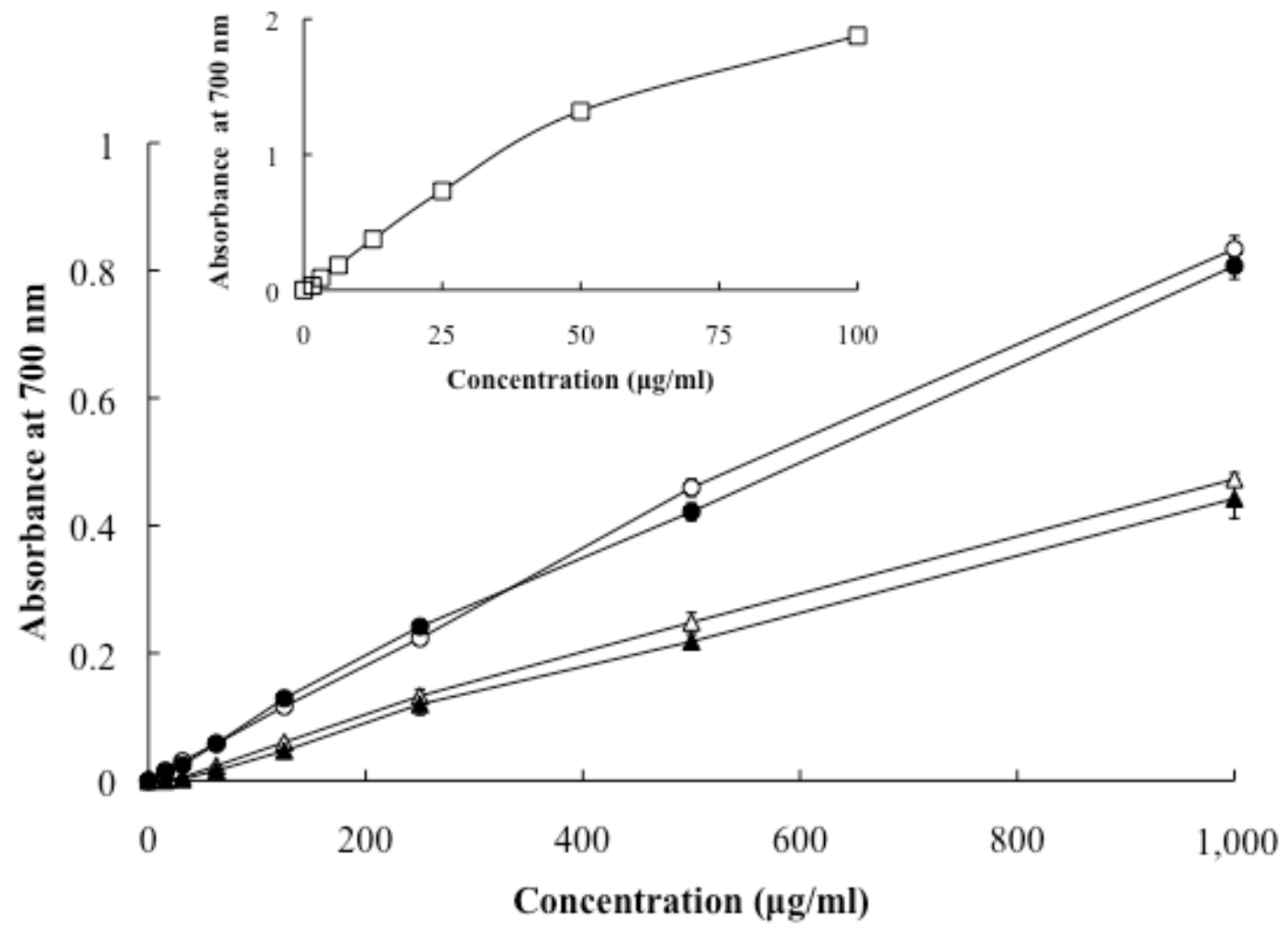

